\title{
OXIDATIVE DEGRADATION OF AQUEOUS PHENOL EFFLUENT WITH ELECTROGENERATED FENTON'S REAGENT
}

\author{
MASAO SUDOH, TAKAMASA KODERA, KUNIO SAKAI, \\ JING QUAN ZHANG AND KOZO KOIDE \\ Department of Chemical Engineering, Shizuoka University, Hamamatsu 432
}

Key Words: Electrolysis, Waste Water Treatment, Phenol, Fenton's Reagent, Hydrogen Peroxide

\begin{abstract}
A novel process of an oxidative degradation of aqueous phenol effuent with hydrogen peroxide produced by electroreduction of oxygen dissolved in the effluent was studied. Effects of operational conditions such as $\mathrm{pH}$, cathode potential, ferrous ion concentration and phenol concentration on the degradation rate of phenol were clarified. Phenol was successively degraded to carbon dioxide at pH 3 with higher efficiency rather than the other pH's. The COD current efficiency at pH 3 was higher than that for the anodic oxidation process of phenol and was more than $60 \%$ for complete degradation in the range of $260-2600 \mathrm{ppm}$ of initial COD.
\end{abstract}

\section{Introduction}

An organic effluent which cannot be easily decomposed by biological action has to be treated by chemical oxidation. There are several methods of chemical oxidation with different oxidants and different additional energies such as ultraviolet rays, electrolysis and high pressure for the wet oxidation process. Among treatments by electrolysis, anodic oxidation $^{1,6)}$ of effluents containing organic compounds has been most often studied. For the oxidative treatment of aqueous phenol effluent by use of a lead dioxide anode, the current efficiency of phenol degradation decreased with decreasing phenol concentration. ${ }^{6}$ This was caused by the decrease in diffusion rate to the electrode with decreasing phenol concentration.

Another application of electrolysis to chemical oxidation process is the method in which the oxidant is generated by electrolysis. Hydrogen peroxide is produced by electroreduction of oxygen dissolved in the effluent and reacts with ferrous ion to form hydroxyl radical, which is a strong oxidant. Electrogenerated Fenton's reagent was used to synthesize the oxidation products of organic substances. ${ }^{2,3,9)}$

For application of electrogenerated Fenton's reagent to waste water treatment, the degradation rate and the products distribution have to be determined. The objective of this paper is to clarify the effects of the various factors on the degradation of aqueous phenol effluent with electrogenerated Fenton's reagent and to discuss the feasibility of this process.

Received May 7, 1986. Correspondence concerning this article should be addressed to M. Suđoh. K. Koide is now at Dept. of Chem. Eng., Tokyo Inst. Tech., Tokyo 152.

\section{Experimental}

The H-type dual-compartment electrolyzer shown in Fig. 1 was used for producing hydrogen peroxide by electroreduction of oxygen and for degrading phenol with electrogenerated Fenton's reagent. The operational conditions are shown in Table 1 . The solution in each compartment was $0.17 \mathrm{dm}^{3}$ in volume, stirred by a magnetic bar and separated by a cation exchange membrane. Oxygen was sparged into the catholyte. The cathode was a graphite plate (EG38, Nippon Carbon Co.) having an effective surface area of $78 \mathrm{~cm}^{2}$ and the anode was a $2 \mathrm{~cm} \times 3 \mathrm{~cm} \mathrm{Pt}$ plate. The catholyte consisted of dilute phenol, ferrous sulfate and a supporting electrolyte of 0.5 mol $\cdot \mathrm{dm}^{-3}$ sodium sulfate. The anolyte contained only the same supporting electrolyte. During the electrolysis, the cathode potential was controlled by a potentiostat (HA-310, Hokuto Denko Co.) with a Luggin capillary connected to the reference electrode, a $\mathrm{Ag} / \mathrm{AgCl}$ electrode in a saturated $\mathrm{KCl}$ solution (abbraviated SSE). The pH in the catholyte was kept constant by a $\mathrm{pH}$-stat (HSM-10M, Toa Electronics Co.). The amount of electricity was monitored by a coulometer.

Experiments of current efficiency for producing hydrogen peroxide were made with catholyte containing only the supporting electrolyte. The concentration of hydrogen peroxide was determined by measuring the light absorption of the titanic-hydrogen peroxide colored complex at $410 \mathrm{~nm}$.

The concentrations of phenol and the oxidation products were identified with a high-performance liquid chromatograph (Hitachi-655) using a column of Zorbax ODS at wavelengths of $210 \mathrm{~nm}$ and $250 \mathrm{~nm}$ for the exclusive use of $p$-quinone. The elute was 


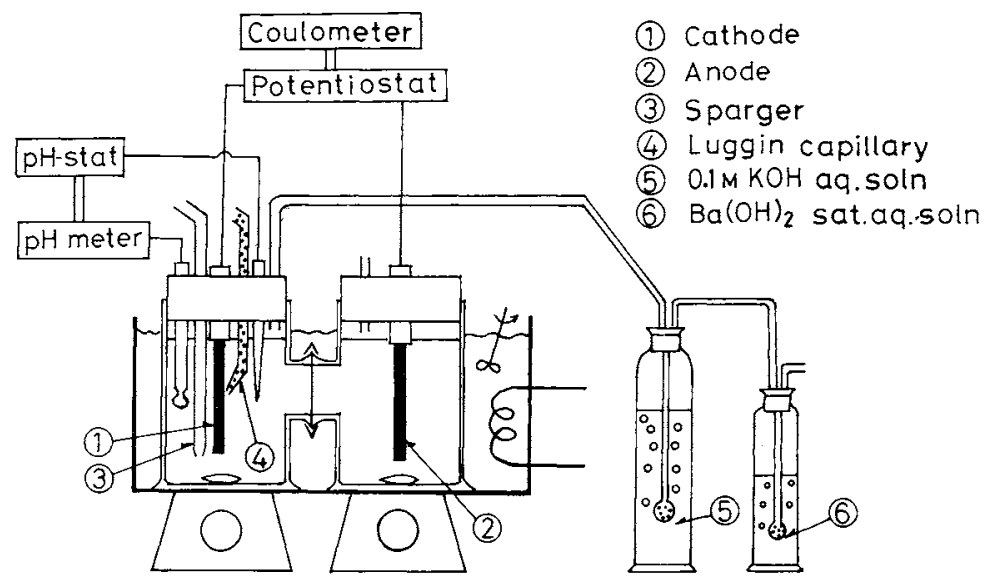

Fig. 1. Diagram of H-type electrolyzer.

Table 1. Experimental conditions

\begin{tabular}{llc}
\hline Cathode potential $-E$ & {$[\mathrm{~V}]$} & $0.2-1.0$ \\
$\mathrm{pH}$ & {$[-]$} & $1.0-4.0$ \\
Reaction temperature & {$[\mathrm{K}]$} & $278-318$ \\
Ferrous ion concentration & {$\left[\mathrm{mol} \cdot \mathrm{m}^{-3}\right]$} & $0.20-50.0$ \\
Oxygen sparging rate & {$\left[\mathrm{cm}^{3} \cdot \mathrm{s}^{-1}\right]$} & $1.50-16.3$ \\
Phenol concentration & {$\left[\mathrm{mol} \cdot \mathrm{m}^{-3}\right]$} & $1.0-12.0$ \\
\hline
\end{tabular}

distilled water degassed by an ultrasonic instrument. Chemical oxygen demand (COD) was measured with potassium dichromate. Carbon dioxide produced was absorbed into a $\mathrm{KOH}$ solution and measured by titration with $\mathrm{HCl}$ using two indicators, phenolphthalein and Methyl Orange indigo carmine.

\section{Results and Discussion}

\subsection{Electrolysis condition for producing hydrogen peroxide}

In acidic solutions, electroreductions of oxygen on a graphite cathode are expressed as follows. ${ }^{8)}$

$$
\begin{aligned}
& \mathrm{O}_{2}+2 \mathrm{H}^{+}+2 \mathrm{e}^{-} \longrightarrow \mathrm{H}_{2} \mathrm{O}_{2} \\
& \mathrm{O}_{2}+4 \mathrm{H}^{+}+4 \mathrm{e}^{-} \longrightarrow 2 \mathrm{H}_{2} \mathrm{O}
\end{aligned}
$$

The current-potential curve and the current efficiency for producing hydrogen peroxide at $100 \mathrm{C}, \mathrm{Ce}$, in an acidic solution, as shown in Fig.2, were different from those in alkaline solutions. ${ }^{4.5)} \mathrm{Ce}$ was affected by $\mathrm{pH}$ and cathode potential $E$ and had its maximum value of $85 \%$ at $\mathrm{pH} 3$ and $-E=0.6 \mathrm{~V}$ vs. SSE. In the range of $\mathrm{pH} \mathrm{1-3,} \mathrm{the} \mathrm{concentration} \mathrm{of} \mathrm{hydrogen} \mathrm{peroxide}$ increased at a constant value of $\mathrm{Ce}$ with increasing electricity amount. Meanwhile, at $\mathrm{pH} \mathrm{4,} \mathrm{the} \mathrm{con-}$ centration of hydrogen peroxide did not increase and $\mathrm{Ce}$ decreased with an electricity amount of more than $200 \mathrm{C}$.

\subsection{Fenton oxidation kinetics with electrogenerated hydrogen peroxide}

The oxidation mechanism of Fenton reaction proposed by Walling ${ }^{10)}$ is assumed.

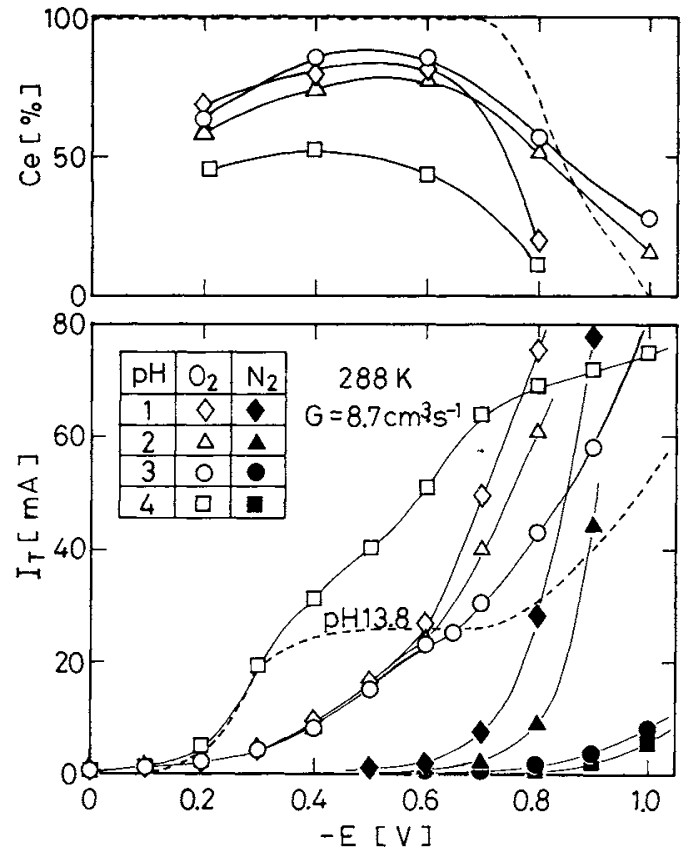

Fig. 2. Current-potential curve and current efficiency for producing hydrogen peroxide at $100 \mathrm{C}$.

$$
\begin{aligned}
& \mathrm{Fe}^{2+}+\mathrm{H}_{2} \mathrm{O}_{2} \stackrel{k_{1}}{\longrightarrow} \mathrm{Fe}^{3+}+\mathrm{OH}^{-}+\mathrm{OH} . \\
& \mathrm{Fe}^{2+}+\mathrm{OH} \cdot \stackrel{k_{2}}{\longrightarrow} \mathrm{Fe}^{3+}+\mathrm{OH}^{-} \\
& \mathrm{RH}+\mathrm{OH} \cdot \stackrel{k_{31}}{\longrightarrow} \mathrm{R}_{1} \cdot+\mathrm{H}_{2} \mathrm{O} \\
& \mathrm{RH}+\mathrm{OH} \cdot \stackrel{k_{32}}{\longrightarrow} \mathrm{R}_{2} \cdot+\mathrm{H}_{2} \mathrm{O} \\
& \mathrm{R}_{1} \cdot+\mathrm{Fe}^{3+} \stackrel{k_{41}}{\longrightarrow} \mathrm{R}_{1}^{+}+\mathrm{Fe}^{2+} \\
& \mathrm{R}_{2} \cdot+\mathrm{Fe}^{2+} \stackrel{k_{42}}{\longrightarrow} \mathrm{R}_{2}^{-}+\mathrm{Fe}^{3+} \stackrel{\mathrm{H}^{+}}{\longrightarrow} \mathrm{RH}
\end{aligned}
$$

With pseudo-steady state assumption for the concentrations of intermediate radicals, the ratio of the decreasing rate of hydrogen peroxide to that of ferrous ion is as follows. 


$$
\frac{-2 \mathrm{~d}\left[\mathrm{H}_{2} \mathrm{O}_{2}\right]}{-\mathrm{d}\left[\mathrm{Fe}^{2+}\right]}=\frac{1+\left(k_{31}+k_{32}\right)[\mathrm{RH}] /\left(k_{2}\left[\mathrm{Fe}^{2+}\right]\right)}{1+k_{32}[\mathrm{RH}] /\left(k_{2}\left[\mathrm{Fe}^{2+}\right]\right)}
$$

When only small amounts of ferrous ion and phenol are consumed, Eq. (9) is equivalent to the ratio using the concentration difference of both substances.

$$
R=\operatorname{ar}(1-R)+b
$$

Where

$$
\begin{aligned}
& R=\left(-\Delta\left[\mathrm{Fe}^{2+}\right]\right) /\left(-2 \Delta\left[\mathrm{H}_{2} \mathrm{O}_{2}\right]\right), r=\left[\mathrm{Fe}^{2+}\right] /[\mathrm{RH}], \\
& a=k_{2} /\left(k_{31}+k_{32}\right) \text { and } b=k_{32} /\left(k_{31}+k_{32}\right) .
\end{aligned}
$$

Then the decreasing rate of phenol is as follows.

$$
\frac{-\mathrm{d}[\mathrm{RH}]}{\mathrm{d} t}=\frac{k_{1} k_{31}[\mathrm{RH}]\left[\mathrm{Fe}^{2+}\right]\left[\mathrm{H}_{2} \mathrm{O}_{2}\right]}{k_{2}\left[\mathrm{Fe}^{2+}\right]+\left(k_{31}+k_{32}\right)[\mathrm{RH}]}
$$

When hydrogen peroxide is generated from oxygen, Eq. (1) has to be added to the Fenton oxidation kinetics mentioned above. Since the produced hydrogen peroxide reacts with ferrous ion and diminishes rapidly, the following pseudo-steady state is assumed.

$$
\begin{aligned}
\mathrm{d}\left[\mathrm{H}_{2} \mathrm{O}_{2}\right] / \mathrm{d} t & =I_{O} /(2 \boldsymbol{F} V)-k_{1}\left[\mathrm{Fe}^{2+}\right]\left[\mathrm{H}_{2} \mathrm{O}_{2}\right] \\
& =0
\end{aligned}
$$

where $I_{O}$ is the current for Eq. (1) and $V$ the catholyte volume.

By arranging Eq. (11) with the relation of Eq. (12),

$$
-\mathrm{d}[\mathrm{RH}] / \mathrm{d} t=(1-b) I_{o} /\{2 F V(1+a r)\}
$$

Figure 3 shows the arrangement of Eq. (10) to determine $a$ and $b$ at different $\mathrm{pH}$ values. At $\mathrm{pH} 3$ and $\mathrm{pH} 4$, the values of $b$ were relatively small, the reduction of ferric ion of Eq. (7) proceeded and ferrous ion was regenerated.

\subsection{Current efficiency of phenol degradation}

Cathodic reactions other than Eqs. (1) and (2) take place on the cathode.

$$
\begin{gathered}
\mathrm{Fe}^{3+}+\mathrm{e}^{-} \longrightarrow \mathrm{Fe}^{2+} \\
2 \mathrm{H}^{+}+2 \mathrm{e}^{-} \longrightarrow \mathrm{H}_{2}
\end{gathered}
$$

The current during the electrolysis, $I_{T}$, is the summation of Eqs. (1), (2), (14) and (15). The current efficiency of phenol degradation, $C e_{P}$, is defined by the following equation.

$$
C e_{P}=(-\Delta[\mathrm{RH}]) 2 F V / Q \times 100 \%
$$

where $Q$ is total coulombs during electrolysis. When hydrogen peroxide generated with an efficiency of $1 \mathrm{~mol}$ per $2 \boldsymbol{F}$ produces $1 \mathrm{~mol}$ of hydroxyl radical to oxidize $1 \mathrm{~mol}$ of phenol, $\mathrm{Ce}_{P}$ indicates $100 \%$. By modifying the differential term of Eq. (13) to a difference term and substituting the term into Eq. (16) with the relation of $Q=I_{T} \Delta t$,

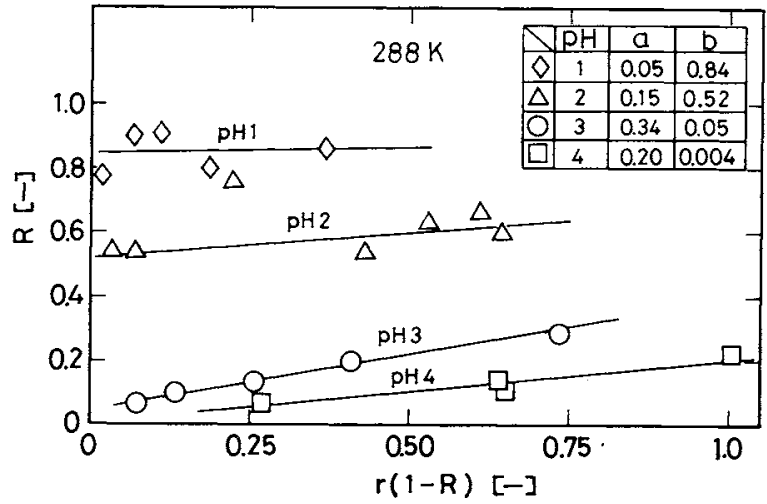

Fig. 3. Arrangement to determine $a$ and $b$ in Fenton oxidation kinetics.

$$
C e_{p}=(1-b) I_{o} /\left\{I_{T}(1+a r)\right\} \times 100 \%
$$

Figures 4, 5 and 6 show comparisons between experimental and estimated values of $C e_{P}$ at $100 \mathrm{C}$, which are respectively given by Eqs. (16) and (17). $C e_{P}$ had its maximum value at a cathode potential of $-E=0.6 \mathrm{~V} . C e_{p}$ at $\mathrm{pH} 3$ was higher than at $\mathrm{pH} 1$ and $\mathrm{pH}$ 2. The effect of $\mathrm{pH}$ on $C e_{p}$ was contributed to by the kinetic parameter $b$, the smaller $b$ resulting in higher $C e_{P}$. The experimental value of $C e_{P}$ had its maximum value at a concentration of ferrous ion of $2 \mathrm{~mol} \cdot \mathrm{m}^{-3}$. Estimated values of $C e_{P}$ agreed well with experimental ones in the concentration range of more than $2 \mathrm{~mol} \cdot \mathrm{m}^{-2}$ of ferrous ion. In the lower concentration range, there is a large deviation between estimated and experimental values. This might be due to the fact that the assumption to introduce the kinetics such as Eqs. (4) and (12) does not hold at lower concentrations of ferrous ion. $C e_{P}$ increased with increasing initial concentration of phenol, as shown in Fig. 6, and agreed well with the estimated value from Eq. (17) using the kinetic parameters, $a$ and $b$, and the ratio of $I_{O}$ to $I_{T}$.

\subsection{Changes of phenol, products and COD with total coulombs}

As reported previously, ${ }^{7)}$ operation in the range of $\mathrm{pH}$ 3-4.5 was effective for degrading phenol with Fenton's reagent. As shown in Fig. 7, at pH 4 the degradation of phenol hardly proceeded with increasing electricity amount because of the decrease in current efficiency of hydrogen peroxide production.

At $\mathrm{pH} 3$, phenol was successively oxidized to organic acids and carbon dioxide, as shown in Fig. 8. The concentration of oxalic acid increased gradually with the electricity amount and had its maximum value around $1000 \mathrm{C}$. It required a total of more than $6000 \mathrm{C}$ to decrease the concentration of oxalic acid below $0.1 \mathrm{~mol} \cdot \mathrm{m}^{-3}$. Since six moles of carbon was theoretically produced from one mole of phenol, the equivalent concentration of carbon dioxide was described as the mole of carbon dioxide, $m\left(\mathrm{CO}_{2}\right)$, divided by 6 and the catholyte volume $V$. At $1800 \mathrm{C}$, 


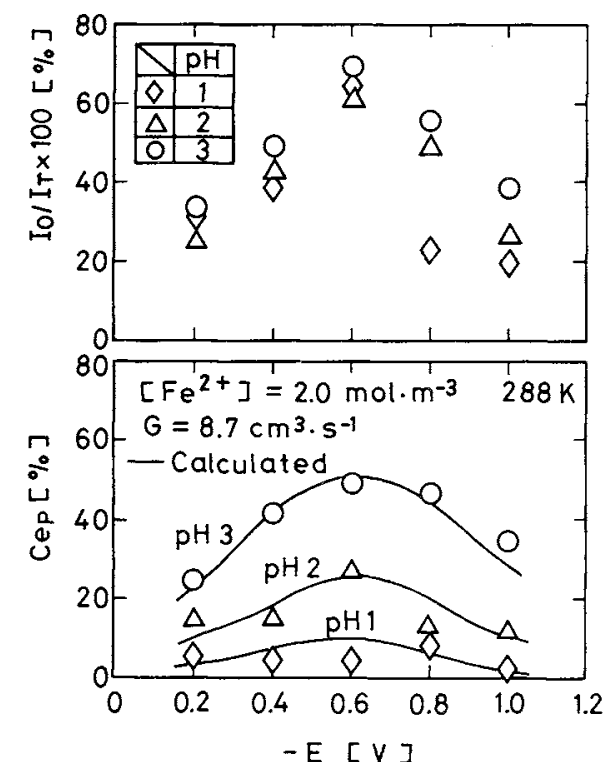

Fig. 4. Effect of cathode potential on current efficiency of phenol degradation when $[\mathrm{RH}]=2.5 \mathrm{~mol} \cdot \mathrm{m}^{-3}$.

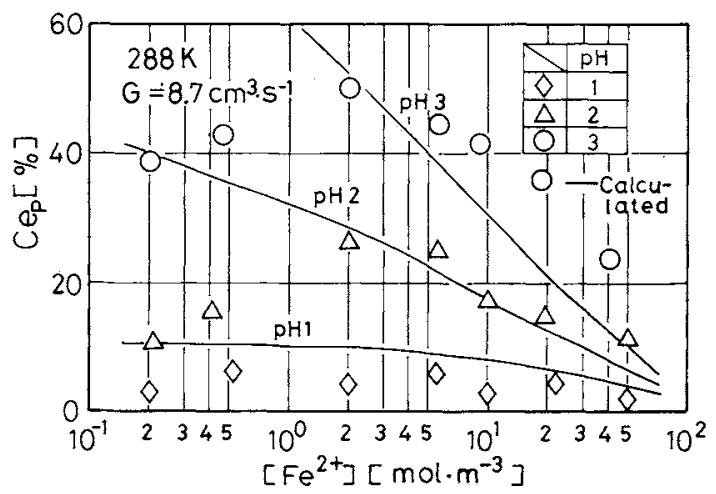

Fig. 5. Effect of ferrous ion concentration on current efficiency of phenol degradation when $[\mathrm{RH}]=2.5 \mathrm{~mol} \cdot \mathrm{m}^{-3}$.

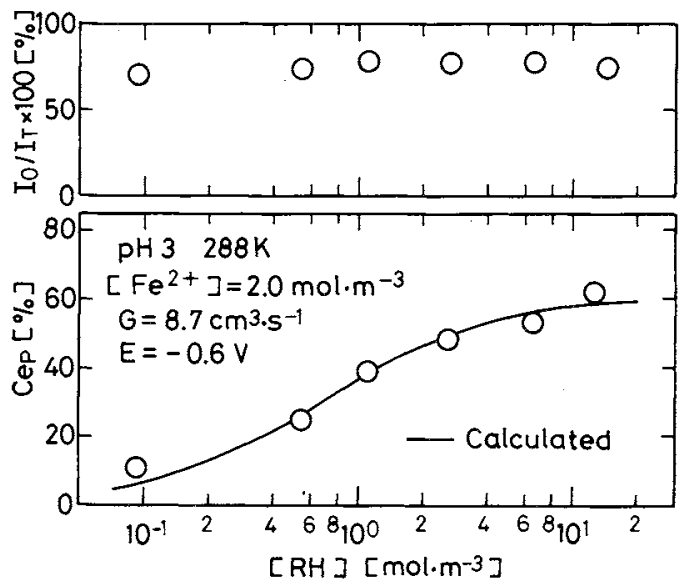

Fig. 6. Effect of phenol concentration on current efficiency of phenol degradation at $\mathrm{pH} 3$

$71 \%$ of initial phenol was converted to carbon dioxide and $96 \%$ of initial COD was reduced.

The degradation rates of phenol with total coulombs at $\mathrm{pH} 2$ and $\mathrm{pH} 1$, as respectively shown in
Figs. 9 and 10, were slower than that at $\mathrm{pH}$ 3. At $\mathrm{pH}$ 2 , the conversion of carbon dioxide and the COD reduction were lower than those at $\mathrm{pH} 3$. At $\mathrm{pH} 1$, the concentrations of the products were extremely low and COD decreased slowly in comparison with the decrease in concentration of phenol. Since tarry precipitates were observed in the reactant solution, the oxidation of phenol might proceed to produce the dimer or trimer of phenol.

\subsection{COD current efficiency}

If hydrogen peroxide is produced with an efficiency of $1 \mathrm{~mol}$ per $2 F$ and $1 \mathrm{~mol}$ of hydroxyl radical reduces COD by $16 \mathrm{~g}$, the theoretical coulombs $Q_{T}$ required to degrade initial COD completely is given by the following equation.

$$
Q_{T}=2 F V\left(\mathrm{COD}_{0}\right) / 16
$$

When the COD current efficiency is $100 \%$, the theoretical COD reduction is equivalent to the value of $16 Q /(2 F V)$. The COD current efficiency is defined as follows.

$$
C e(\mathrm{COD})=\frac{\mathrm{COD} \text { reduction }}{16 Q /(2 \boldsymbol{F V})} \times 100 \%
$$

Figure 11 shows the change of $C e(C O D)$ and the conversion of COD with the ratio of total coulombs to the theoretical coulombs according to the initial COD. $C e(C O D)$ decreased with increasing total coulombs and was higher than $C e_{P}$ for phenol degradation. $C e(C O D)$ of more than $100 \%$ might be caused by the autooxidation of intermediate products by degradation of phenol with oxygen other than hydroxyl radical. $\mathrm{Ce}(\mathrm{COD})$ at $\mathrm{pH} 3$ was higher than that for the anodic oxidation process of phenol ${ }^{6}$ and was more than $60 \%$ for complete degradation in the range of $260-2600 \mathrm{ppm}$ of initial COD.

The current during the electrolysis, $I_{T}$, increased with incresing reaction temperature $T$ and the oxygen sparging rate $G$. Meanwhile, the degradation rate of phenol with total coulombs was less affected by the factors $T$ and $G$, as shown in Fig. 12 .

\section{Conclusion}

The effects of $\mathrm{pH}$, ferrous ion concentration, phenol concentration and cathode potential on the current efficiency of phenol degradation were clarified by a combination of the kinetics of Fenton oxidation and the ratio of the current for producing hydrogen peroxide to total current. Phenol was oxidatively degraded to oxalic acid and carbon dioxide at $\mathrm{pH} 3$ with a higher efficiency than at other $\mathrm{pH}$ values. The COD current efficiency at $\mathrm{pH} 3$ was higher than that for the anodic oxidation process of phenol and was more than $60 \%$ for complete degradation in the range of 260-2600 ppm of initial COD. 


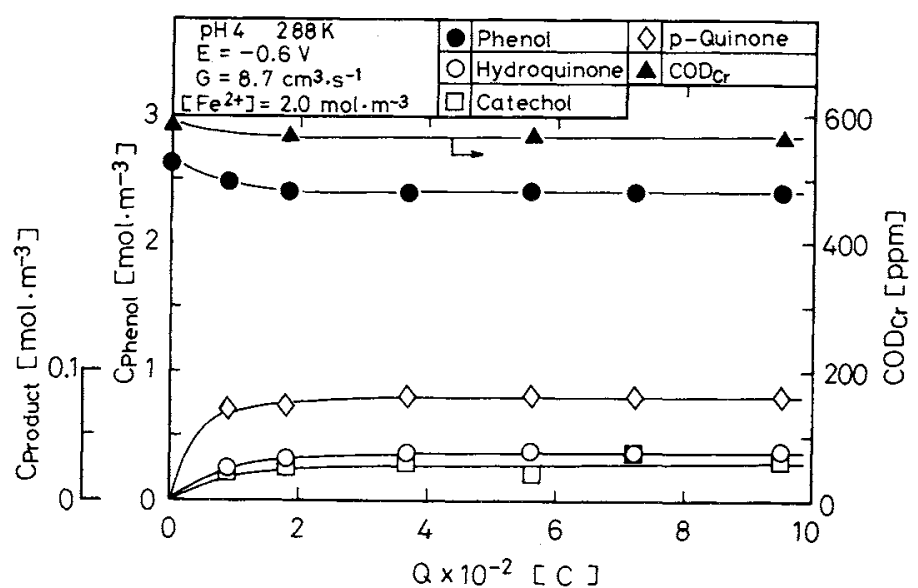

Fig. 7. Changes of phenol, products and $\mathrm{COD}$ with total coulombs at $\mathrm{pH} 4$.

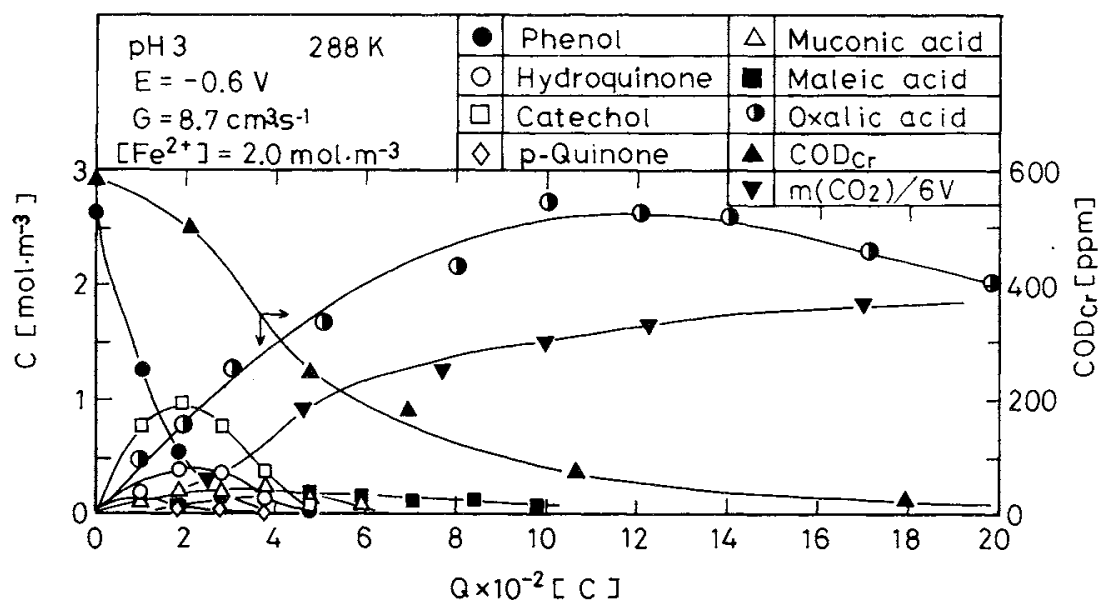

Fig. 8. Changes of phenol, products and $\mathrm{COD}$ with total coulombs at $\mathrm{pH} 3$.

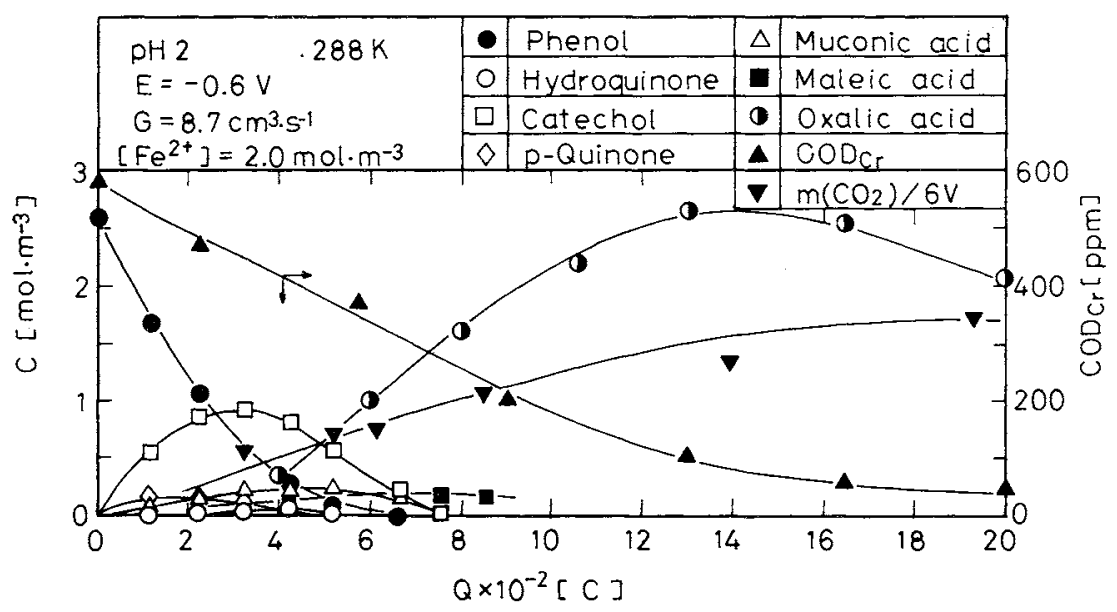

Fig. 9. Changes of phenol, products and COD with total coulombs at $\mathrm{pH} 2$.

\section{Acknowledgment}

This work was supported by a Grant-in-Aid for Special Research on Environmental Science (No. 60030017) from the Ministry of Education, Science and Culture of Japan.

\section{Nomenclature}

a $\quad=k_{2} /\left(k_{31}+k_{32}\right)$, ratio of rate constant

$b \quad=k_{32} /\left(k_{31}+k_{32}\right)$, ratio of rate constant
$C \quad=$ concentration

$\left[\mathrm{mol} \cdot \mathrm{m}^{-3}\right]$

$\mathrm{Ce} \quad=$ current efficiency for producing hydrogen peroxide

$\mathrm{Ce}_{p} \quad=$ current efficiency for degrading phenol defined by Eq. (16) [\%]

$\mathrm{Ce}(\mathrm{COD})=\mathrm{COD}$ current efficiency defined by Eq. (19) $\quad[\%]$

[-] $E \quad=$ cathode potential

[V]

$[-] \quad F \quad=$ Faraday's constant

$\left[\mathrm{C} \cdot \mathrm{mol}^{-1}\right]$ 


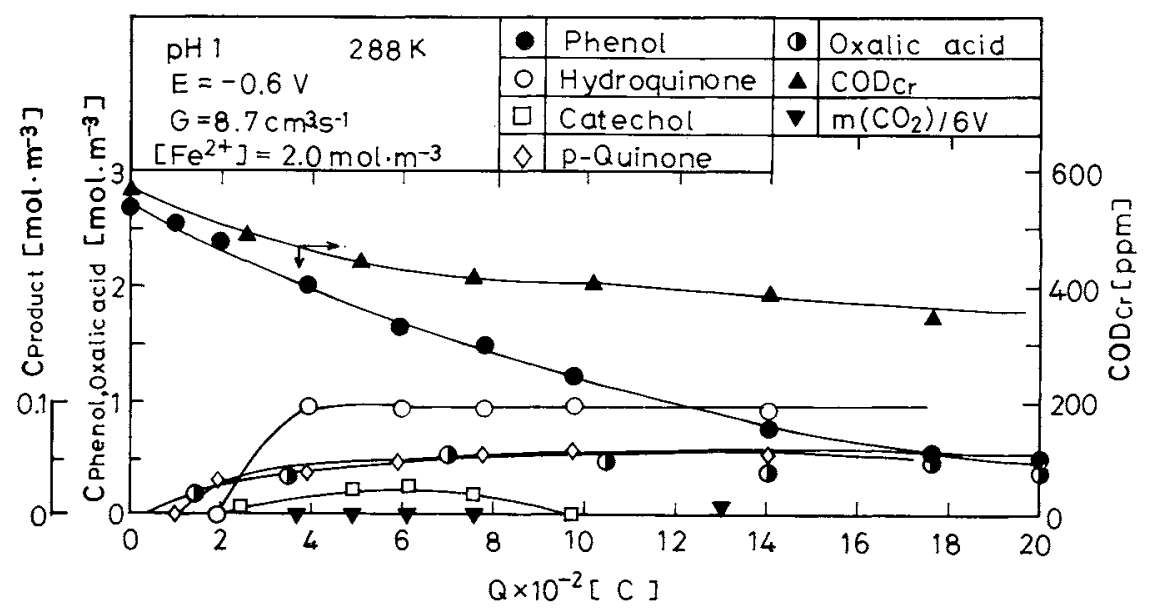

Fig. 10. Changes of phenol, products and COD with total coulombs at $\mathrm{pH} 1$.

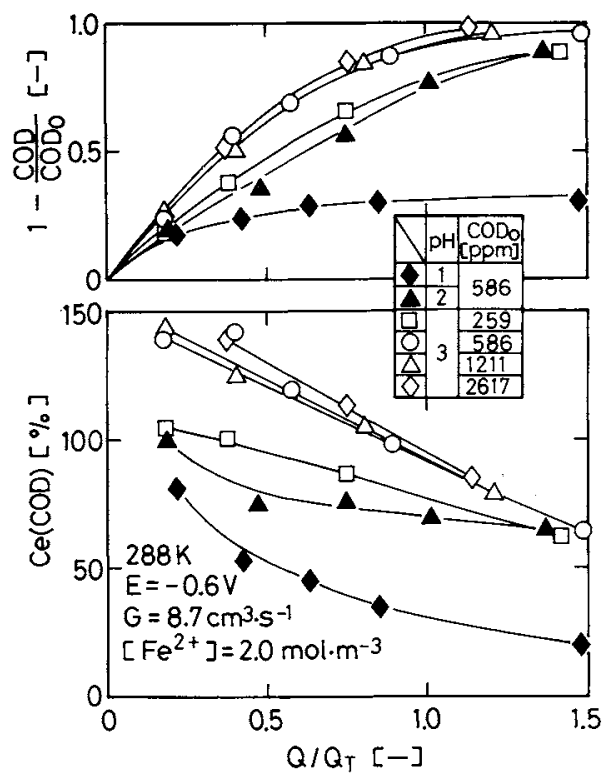

Fig. 11. Relation between COD current efficiency and total coulombs at different values of initial COD.

\begin{tabular}{|c|c|c|}
\hline$G$ & $=$ oxygen sparging rate & $\left.m^{3} \cdot s^{-1}\right]$ \\
\hline$I_{O}$ & $=$ current for producing hydrogen peroxide & \\
\hline$I_{T}$ & $=$ total current during electrolysis & \\
\hline$k_{1}, k_{2}$ & $\begin{array}{l}k_{32}, k_{41}, k_{42} \\
=\text { reaction rate constants }\end{array}$ & \\
\hline$m\left(\mathrm{CO}_{2}\right)$ & $=$ moles of carbon dioxide produced & {$[\mathrm{mc}$} \\
\hline$Q$ & $=$ total coulombs during electrolysis & \\
\hline$Q_{T}$ & $=$ theoretical coulombs defined by Eq. (18) & \\
\hline$R$ & $\begin{aligned}= & \left(-\Delta\left[\mathrm{Fe}^{2+}\right]\right) /\left(-2 \Delta\left[\mathrm{H}_{2} \mathrm{O}_{2}\right]\right), \text { ratio of } \\
& \text { concentration difference }\end{aligned}$ & \\
\hline RH & $=$ phenol & \\
\hline $\mathrm{R}_{1} \cdot, \mathrm{R}_{2} \cdot$ & $=$ intermediate radicals & \\
\hline $\mathrm{R}_{1}^{+}, \mathrm{R}_{2}^{-}$ & $=$intermediate radicals & \\
\hline$r$ & $=\left[\mathrm{Fe}^{2+}\right] /[\mathrm{RH}]$, ratio of concentration & \\
\hline$t$ & $=$ time & \\
\hline$V$ & $=$ catholyte volume & {$[\mathrm{m}$} \\
\hline$\Delta$ & $=$ difference value & \\
\hline
\end{tabular}

$\langle$ Subscript $\rangle$

$0 \quad=$ initial value

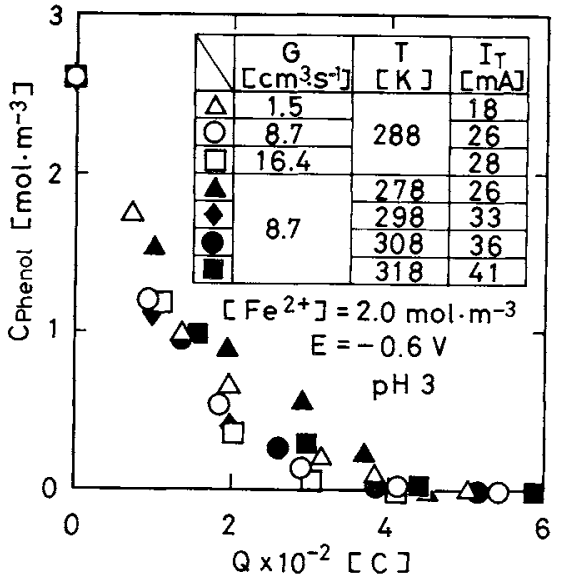

Fig. 12. Effects of reaction temperature and oxygen sparging rate on degradation of phenol.

\section{Literature Cited}

1) Chettia, M. and A. P. Watkinson: Can. J. Chem. Eng., 61, 568 (1983).

2) Fleszar, B. and A. Sobkowiak: Electrochim. Acta, 28, 1315 (1983).

3) Matsue, T., M. Fujihira and T. Osa: J. Electrochem. Soc., 128, 2565 (1981)

4) Sudoh, M., H. Kitaguchi and K. Koide: J. Chem. Eng. Japan, 18, 364 (1985).

5) Sudoh, M., H. Kitaguchi and K. Koide: J. Chem. Eng. Japan, 18, 409 (1985).

6) Sudoh, M., N. Nomura and K. Koide: Kagaku Kogaku Ronbunshu, 10, 43 (1984).

7) Sudoh, M., T. Sasase, T. Yonebayashi and K. Koide: Kagaku Kogaku Ronbunshu, 11, 70 (1985).

8) Taylor, R. J. and A. A. Humffray: $J$. Electroanal. Chem., 64, 85 (1975)

9) Tomat, R. and A. Rigo: J. Appl. Electrochem., 14, 1 (1984).

10) Walling, C.: Acc. Chem. Res., 8, 125 (1975).

(Presented in part at the 19th Fall Meeting of The Society of Chemical Engineers, Japan at Nagoya Oct. 18, 1985.) 